\title{
PEMBERDAYAAN POTENSI ALAM DAN SUMBER DAYA MANUSIA UNTUK MENINGKATKAN PEREKONOMIAN PADA DESA AIR GLUBI
}

\section{Empowering the Potential of Nature and Human Resources to Improve the Economy in Air Glubi Village}

\author{
Selvi Fauzar ${ }^{1 *}$ \\ ${ }^{1)}$ Program Studi Manajemen, Sekolah Tinggi Ilmu Ekonomi Pembangunan, Tanjungpinang \\ *Korespondensi : selvifauzar@gmail.com
}

\begin{abstract}
ABSTRAK
Pemanfaatan sumber daya alam yang ada di Desa Air Glubi sangat penting dan memberikan potensi yang besar pada perekonomian masyarakat Desa Air Glubi, yang sebagian besar sumber daya yang ada belum dikelola secara maksimal diantaranya sumber daya alam berupa ikan yang bisa diolah menjadi kerupuk otak - otak dan pemanfaatan air laut yang diolah melalui tahapan proses menjadi garam dari hasil ini tentunya memiliki nilai yang sangat bermanfaat bagi masyarakat untuk meningkatkan perekonomian selain itu dari pengabdian ini adalah untuk memberdayakan dan menumbuhkan jiwa kewirausahaan masyarakat Desa Air Glubi. Adapun metode yang digunakan untuk memperoleh data dengan cara observasi dan wawancara sebagai data yang digunakan nantinya dalam melakukan program pengabdian masyarakat. Hasil yang didapatkan dalam pengabdian ini untuk meningkatkan kemampuan masyarakat dalam mengelola ikan hasil tangkapan dan mampu mengelola air laut menjadi garam untuk kebutuhan sehari-hari dan mampu menjadi produk yang bisa dipasarkan, dan nantinya akan menjadi pendapatan ekonomi dan sekaligus menjadi produk unggulan masyarakat Air Glubi.
\end{abstract}

Kata kunci : Pemberdayaan, Potensi, Sumber Daya Alam, Sumber Daya Manusia, Ekonomi

\begin{abstract}
Utilization of natural resources in Air Glubi Village are important and gives great potential to the economy of the community of Air Glubi Village, where most of the available resources have not been managed optimally including natural resources in the form of fish that can be processed into crackers and the utilization of sea water is being processed through the stages to become salt from these results certainly has a value that is beneficial for the community to improve the economy in addition to this service is to empower the entrepreneurial spirit of the community of Air Glubi Village. The method used to obtain data through observation and interviews as data used later in conducting community service programs. The results obtained in this service are to improve the ability of the community to manage catch fish and be able to manage sea water into salt for daily needs and be able to be a product that can be marketed, and later will be an economic income and at the same time become a superior product of the Air Glubi community.
\end{abstract}

Keyword : Empowerment, Potential, Natural Resources, Human Resources, Economy 


\section{PENDAHULUAN}

Desa Air Glubi merupakan pemekaran dari Desa Kelong Kecamatan Bintan Pesisir pada tanggal 20 Agustus 2007 yang ditetapkan dengan Peraturan Daerah (Perda) Kabupaten Bintan Nomor 11 tahun 2007 tentang Pembentukan. Kelurahan dan desa sekitar bintan.

Masyarakat di Desa Air Glubi, Kepulauan Riau, Kabupaten Bintan Kecamatan Bintan Pesisir adalah masyarakat yang ada di daerah kepulauan, yang mayoritas masyarakatnya bekerja sebagai nelayan karena berada di dekat laut. Khusus di daerah ini terdapat berbagai jenis ikan yang awalnya hanya dimanfaatkan sebagai makanan sehari-hari bagi masyarakat dan air laut yang pemanfaatannya belum maksimal dengan potensi produk turunan dari bahan baku air laut, dengan potensi sumber daya alam yang besar dan melimpah, maka sangat penting untuk memaksimalkan potensi yang ada untuk meningkatkan ekonomi dan kesejahteraan masyarakat diantaranya dengan mengelola sumber daya alam yang berupa ikan laut menjadi olahan kerupuk otak-otak dan memanfaatkan air laut yang dikelola menjadi garam untuk di produksi sehingga kedua produk tersebut bisa menjadi produk unggulan masyarakat Desa Air Glubi.

Permasalahan pada masyarakat Desa Air Glubi mengenai minimnya pengetahuan dan bagaimana melihat peluang sumber daya yang ada belum maksimal menjadikan sumber pendapatan ekonomi serta menumbuhkan jiwa kewirausahaan dengan kemampuan dan pengetahuan untuk mengelola potensi alam di desanya menjadi peluang usaha, dengan cara-cara sederhana masyarakat sudah bisa menghasilkan produk olahan yang berbahan baku dari sumber alam disekitar desa.

Pemberian wawasan dan pengetahuan dalam melihat potensi yang ada di desa Air Glubi kepada masyarakat dan nantinya masyarakat mampu memaksimalkan sumber alam yang ada, dan kemudian masyarakat mampu memproduksi menjadi produk unggulan yang dihasilkan oleh masyarakat Desa Air Glubi, dengan ciri khas daerah kepulauan yang sumber daya alam berupa penghasil ikan maka, beberapa produk turunan menjadi sebuah ide terbaik untuk melakukan inovasi sebuah produk makanan yang khas dari daerah tersebut, berupa kerupuk otak-otak berbahan dasar ikan, serta ketersediaannya air laut yang tak terbatas ini menjadi sebuah potensi untuk diolah menjadi garam dan dapat berkembang menjadi pendapatan ekonomi dalam meningkatan kesejahteraan masyarakat secara luas

Tujuan yang ingin dicapai melalui kegiatan pengabdian ini adalah untuk memberdayakan masyarakat Desa Air Glubi dengan cara memberikan pelatihan demonstrasi pembuatan kerupuk otak-otak dan pengelolaan air laut menjadi garam, yang merupakan salah satu peluang usaha yang menjanjikan sesuai dengan potensi sumber daya alam yang ada di desa tersebut, yang nantinya diharapkan dapat menjadi usaha yang menguntungkan dari segi peningkatan ekonomi di daerah tersebut, sehingga roda perekonomian dapat bergerak menjadi lebih baik untuk kedepannya. Pelatihan dengan cara mengajak masyarakat bagaimana pengelolahan sumber daya alam yang ada di desanya menjadi produk-produk yang bernilai ekonomi, dan menjadi masyarakat yang mandiri tidak ketergantungan produk dari luar desa selama ada peluang yang bisa di hasilkan dari desanya sendiri, berupa olahan kerupuk berbahan dasar ikan dan pengelolahan garam yang berbahan dasar air laut di desa Air Glubi yang sangat perpotensi menjadi produk unggulan. Ini merupakan langkah yang sangat penting untuk membantu masyarakat menciptakan ide-ide yang berkelanjutan membangun kekuatan ekonomi yang sangat besar potensinya. Masyarakat mampu mengelolah sumber daya alam yang ada menjadi sumber pendapatan ekonomi tambahan maupun menjadi pendapatan utama selain sebagai nelayan yang menjual secara langsung hasil tangkapan kepada tengkulak atau pengepul di kecamatan Kijang Timur, tanpa meningkatkan nilai jual lebih dengan mengelolah hasil dari menangkap ikan dan memanfatan air laut menjadi garam menjadikan peluang untuk memenuhi kebutuhan sehari-hari maupun menjadi 
produk yang bernilai jual.

\section{METODE}

\section{Waktu dan Tempat}

Kegiatan dilaksanakan selama 3 bulan yang diselenggarakan dari tanggal 1 Juni 2021 - 1 September 2021 di Desa Air Glubi, Kecamatan Bintan Pesisir, Kabupaten Bintan, Provinsi Kepulauan Riau.

\section{Prosedur Pelaksanaan dan Analisis Data}

Kegiatan yang dilakukan yaitu memberikan pembelajaran kegiatan kewirausahaan kepada masyarakat yang tergabung kedalam Kelompok Usaha Bersama (KUBE) Sri Rampai Desa Air Glubi, pemberian sosialisasi sekaligus mempratekkan bagaimana mengelolah sumber alam berupa ikan menjadi olahan kerupuk otak-otak dan pengelolahan air laut diolah menjadi garam. Ruang lingkup dalam kegiatan pengabdian ini kepada masyarakat Desa Air Glubi dan yang tergabung di dalam Kelompok Usaha Bersama (KUBE) Sri Rampai yang di pimpin oleh Ibu Tri sekaligus sebagai penggerak dan mengajak masyarakat untuk datang menghadiri kegiatan-kegiatan kewirausahaan dalam rangka akan adanya kegiatan pengabdian masyarakat oleh mahasiswa STIE Pembangunan Tanjungpinang. Beberapa bahan yang menjadi keperluan dalam melakukan kegiatan yaitu sesuai dengan judul kegiatan kewirausahaan berupa pembuatan kerupuk otak-otak dan garam maka bahan dan alat utama untuk pembuatan kerupuk otak-otak berupa; ikan, tepung terigu, bumbu otak-otak, bumbu penyedap, minyak goreng, air, sedangkan untuk garam hanya membutuhkan bahan Air Laut yang sudah disaring dan disimpan selama lima hari sebagai proses penuaan air laut supaya hasil garam yang diolah menjadi maksimal. Serta alat untuk mendukung proses pembuatan kerupuk otakotak berupa alat-alat masak diantaranya kompor gas, tabung gas, kuali, daun pisang, pisau, penggiling daging manual, sarung tangan plastik, sedangkan alat-alat untuk pembuatan garam terdiri dari; plastik kemasan (bungkus), panci dan penyaring air.

\section{HASIL DAN PEMBAHASAN}

Setelah melakukan kegiatan pengabdian selama 3 bulan di Desa Air Glubi, serangkaian kegiatan pengabdian masyarakat dalam wujud pemberian pengetahuan bagaimana memanfaatkan sumber daya alam secara maksimal dan sumber daya manusia yang memiliki pengetahuan berwirausaha sehingga meningkatkan perekonomian keluarga maupun masyarakat sekitarnya yang akan saling mengajak satu sama lain menumbuhkan semangat berwirausaha.

Dari program kegiatan yang telah dijalankan adapun outcome yang dihasilkan adalah masyarakat memiliki wawasan dan juga keterampilan bagaimana cara membuat kerupuk otak-otak dan juga mengelola air laut menjadi garam, serta menumbuhkan semangat berwirausaha sehingga diharapkan kedepannya roda perekonomian masyarakat Desa Air Glubi dapat berjalan secara berkesinambungan. Beberapa kegiatan pengabdian masyarakat Kelompok 12, bidang kewirausahaan yang terdiri dari empat kelompok kecil salah satunya dibidang kewirausahaan maka dalam kegiatan ini mengambil tema "Pemberdayaan Potensi Alam dan SDM Untuk Meningkatkan Perekonomian Pada Desa Air Glubi" di Kecamatan Bintan Pesisir, Kabupaten Bintan, Provinsi Kepulauan Riau. Diantaranya kegiatan pengabdian masyarakat oleh tema kewirausahaan diantaranya dari beberapa tahapan :

\section{a. Pembuatan kerupuk otak-otak}

Setelah melakukan serangkaian sosialisasi kepada masyarakat dan kepada perangkat desa, diantaranya Kades Air Glubi Bapak Adi Suryanto maka disepakati pada tanggal 16 Juni 2021, hari Rabu menjadi waktu pembukaan kegiatan dan sekaligus menjadi kegiatan program pertama kewirausahaan kepada masyarakat yang diantaranya juga tergabung ke dalam Kelompok Usaha Bersama (KUBE) Sri Rampai, kegiatan 
kewirasuahaan yang menjadi program yaitu pengolahan ikan hasil tangkapan nelayan masyarakat setempat diolah menjadi kerupuk otak-otak yang berbahan dasar ikan. Kegiatan pembuatan kerupuk otak-otak dapat dilihat pada Gambar 1. guna pemanfaatan sumber daya alam yang tersedia pada Air Glubi . kegiatan ini memberikan nilai yang positif untuk menumbuhkan wawasan dan pemberian pembelajaran yang tepat agar kegiatan yang sudah diadakan ini dapat terus berlanjut dan

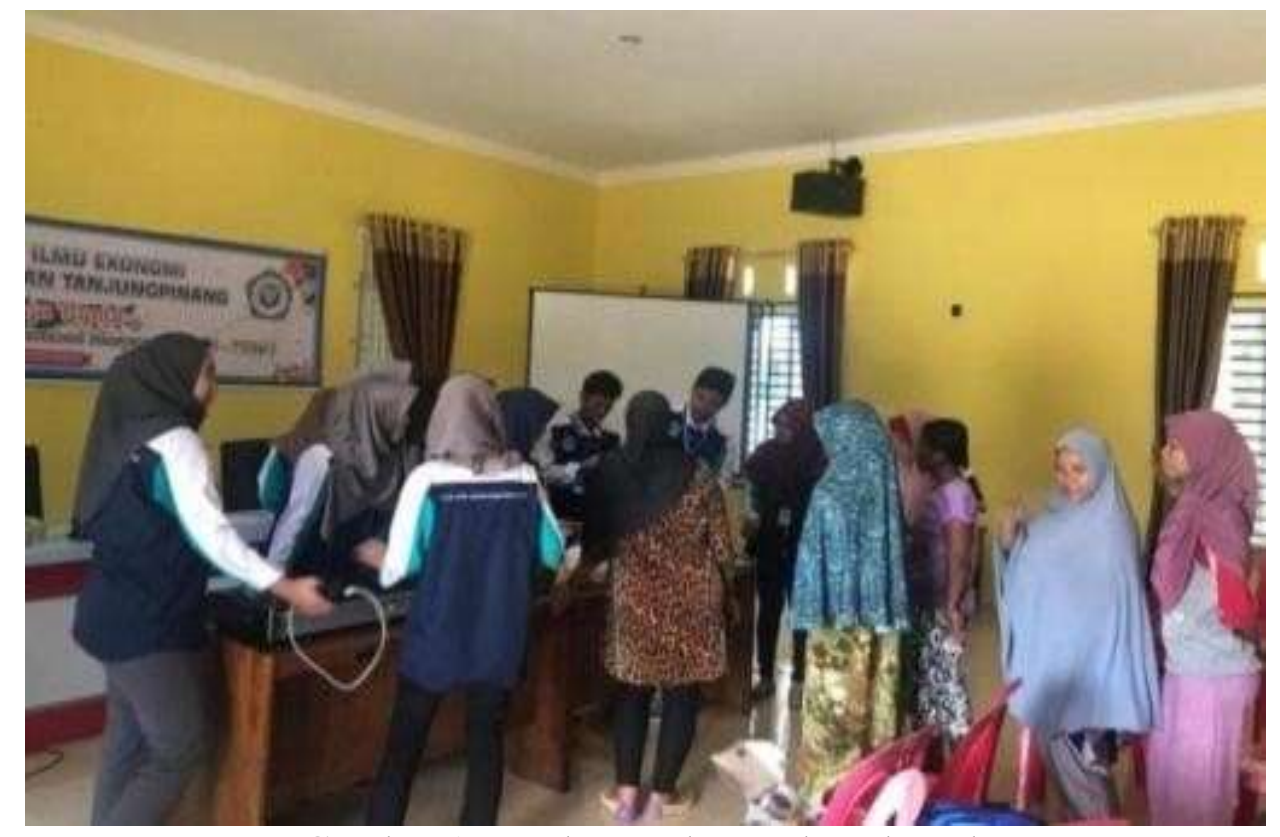

Gambar 1. Pembuatan kerupuk otak-otak

\section{b. Pembuatan Garam}

Kegiatan lanjutan setelah kegiatan pertama pembuatan kerupuk otak-otak diantaranya yang menjadi program dari bidang kewirausahaan yaitu pembuatan garam yang berbahan dasar utama air laut yang diambil langsung di Desa Air Glubi dan disimpan selama lima hari untuk menuakan air laut sebelum diproses menjadi garam. Yang dilaksanakan dua minggu kemudian setelah pembuatan kerupuk otak-otak yantu pada tanggal 3 Juli 2021, hari Sabtu setelah melakukan kegiatan gotong royong Bersama masyarakat dan kelompok ibu PKK di lingkungan Desa Air Glubi, Adapun wujud pengabdian selanjutnya adalah kegiatan membuat garam dengan cara sederhana kepada masyarakat dan ibu-ibu Kelompok Usaha Bersama (KUBE) Sri Rampai (Gambar 2).

Masyarakat sangat antusias mengikuti kegiatan ini yang dibantu oleh mahasiswa/i STIE dalam penyelenggaraan kegiatan pengabdian kepada Masyarakat Air Glubi diadakan evaluasi serta perbaikan kedepannya guna kemajuan dan kesejahteraan perekonomian masyarakat pada Desa Air Glubi. Hasil ini sejalan dengan yang telah dilakukan oleh (Nina \& Rhihfenty, 2018) didalam jurnalnya "Pengabdian kepada masyarakat merupakan salah satu tridharma perguruan tinggi yang dilakksanakan perguruan tinggi dengan bertujuan memberikan kontribusi/membantu meningkatkan berbagai kebutuhan masyarakat serta memecahkan berbagai masalah yang dihadapi masyarakat agar kesejahteraan masyarakat menjadi meningkat. Dengan demikian diharapkan pembuatan kerupuk otak-otak dan garam ini dapat dilanjutkan oleh masyarakat Desa Air Glubi sebagai salah satu sumber pendapatan mereka.

\section{KESIMPULAN}

Pengabdian yang telah dilaksanakan memberikan edukasi kepada masyarakat 
mengenai pentingnya memaksimalkan potensi alam dan SDM yang ada di Desa Air Glubi dan melalui program kegiatan kewirausahaan kepada masyarakat serta Kelompok Usaha Bersama (KUBE) Sri Rampai, sangat memberikan manfaat kepada masyarakat untuk menumbuhkan semangat jiwa kewirausahaan dan agar memiliki wawasan untuk berwirausaha sehingga meningkatkan kesejahteraan hidup keluarganya. Saran yang diberikan perlunya perhatian dari pemerintah pusat dan pemerintah daerah beserta jajarannya sampai ditingkat desa agar mempunyai visi dan misi dalam pembangunan daerah tanpa meninggalkan peran masyarakat dalam memaksimalkan potensi alam secara berkelanjutan tanpa merusak ekosistem alam disekitar yang nantinya akan berdampak kepada kelestarian lingkungan sekitar.
Lasabuda R. 2013. Pembangunan Wilayah Pesisir dan Lautan dalam Perspektif Negara Kepulauan Republik Indonesia, Jurnal Ilmiah Platax, 1(2).

Nina I, \& Rihfenti ESNA. 2018. Peningkatan SDM Melalui Pemberdayaan Kepedulian Sosial, Lingkungan Serta Ekonomi Masyarakat Kelurahan Gunung Samarinda Kota Balikpapan, Jurnal Abdi Masyarakat Ilmu Ekonomi, 01.

Rifa'i B. 2013. Efektivitas Pemberdayaan Usaha Mikro Kecil dan Menengah (UMKM) Krupuk Ikan dalam Program Pengembengan Labsite Pemperdayaan Masarakat Desa Kedung Rejo Kecamatan Jabon Kabupaten Sidoarjo, Kebijakan dan Manajemen Publik, 1.

Siregar R. 2017. Sumber Daya Manusia dalam Pembangunan Nasional. Prosiding Seminar Nasional Tahunan.

Suparmono. 2018. Pengantar Ekonomi

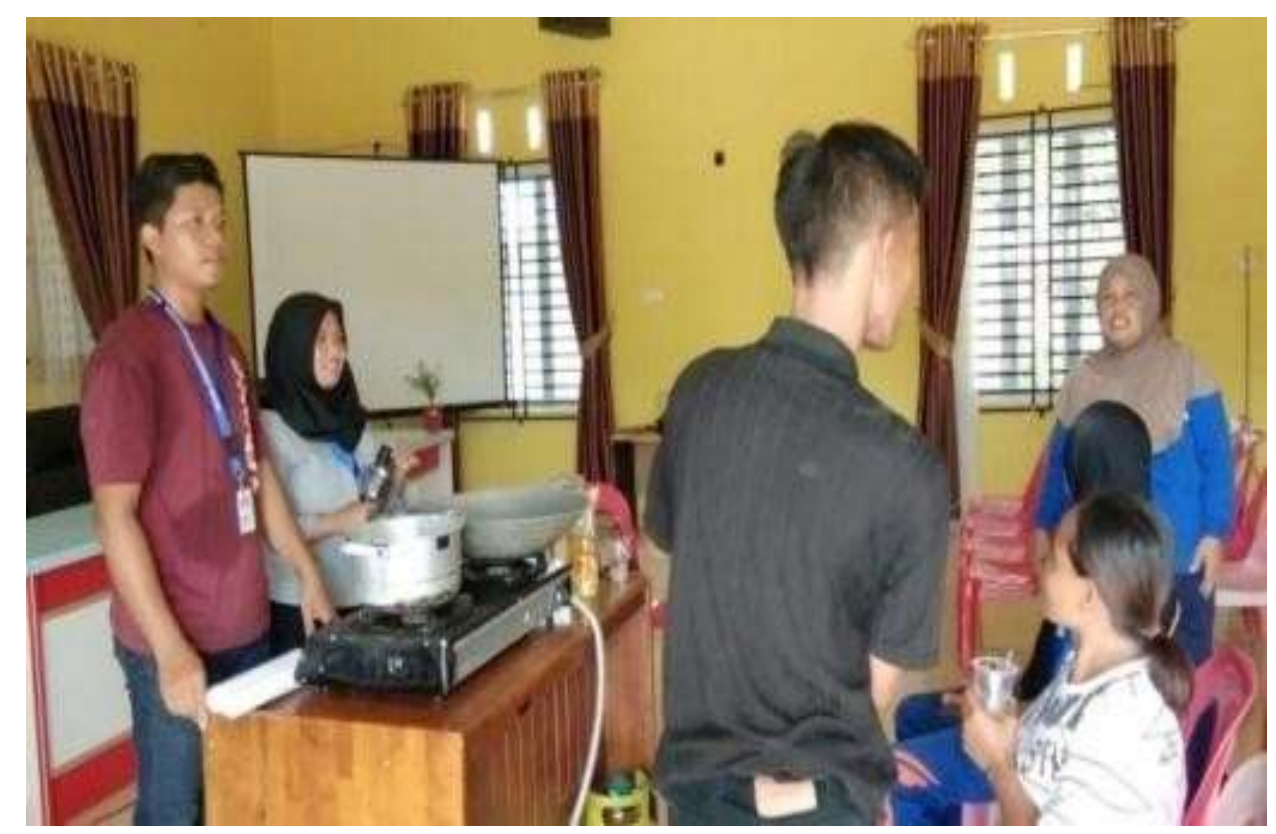

Gambar 2. Penyuluhan tentang pembuatan garam

\section{DAFTAR PUSTAKA}

Dasar - Dasar Sumber Daya Alam Menurut Para Ahli. (n.d.). Retrieved November 4, 2019, from https://www.skokul.com

Farida H. 2014. Kamus Ilmiah Populer Lengkap. Surabaya: Apollo.
Makro. Yogyakarta: UPP-STM YKPN. Zakky. 2019. Pengertian Sumber Daya Alam Menurut Para Ahli Beserta Definisinya.

Zulgani J. 2011. Peranan Sumberdaya Ekonomi Dalam Pembangunan Ekonomi Daerah. Jurnal Pembangunan Daerah Edisi III. 